OPEN ACCESS

Edited by:

Ayelet Fishman,

Technion Israel Institute of

Technology, Israel

Reviewed by:

Pere Clapés,

Instituto de Química Avanzada de Cataluña (IQAC), Spain

Jin-Song Gong,

Jiangnan University, China

*Correspondence:

Kateryna Fesko

kateryna.lypetska@tugraz.at

Specialty section:

This article was submitted to Industrial Biotechnology,

a section of the journal

Frontiers in Bioengineering and

Biotechnology

Received: 22 February 2019 Accepted: 07 May 2019

Published: 28 May 2019

Citation:

Fesko K (2019) Comparison of L-Threonine Aldolase Variants in the Aldol and Retro-Aldol Reactions. Front. Bioeng. Biotechnol. 7:119. doi: 10.3389/fbioe.2019.00119

\section{Comparison of L-Threonine Aldolase Variants in the Aldol and Retro-Aldol Reactions}

\author{
Kateryna Fesko* \\ Institute of Organic Chemistry, Graz University of Technology, Graz, Austria
}

Most of biochemical and mutagenesis studies performed with L-threonine aldolases were done with respect to natural activity, the cleavage of L-threonine and sometimes $L-\beta$-phenylserine. However, the properties of variants and the impact of mutations on the product synthesis are more interesting from an applications point of view. Here we performed site-directed mutagenesis of active site residues of $L$-threonine aldolase from Aeromonas jandaei to analyze their impact on the retro-aldol activity and on the aldol synthesis of $L-\beta$-phenylserine and $L-\alpha$-alkyl- $\beta$-phenylserines. Consequently, reduced retro-aldol activity upon mutation of catalytically important residues led to increased conversions and diastereoselectivities in the synthetic direction. Thus, L- $\beta$-phenylserine can be produced with conversions up to $60 \%$ and d.e.'s up to $80 \%$ (syn) under kinetic control. Furthermorem, the donor specificity of L-threonine aldolase was increased upon mutation of active site residues, which enlarged the pocket size for an efficient binding and stabilization of donor molecules in the active site. This study broadens the knowledge about L-threonine aldolase catalyzed reactions and improves the synthetic protocols for the biocatalytic asymmetric synthesis of unnatural amino acids.

Keywords: biocatalysis, asymmetric synthesis, amino acids, threonine aldolase, aldol reaction

\section{INTRODUCTION}

L-threonine aldolases (LTAs) catalyse the reversible cleavage of L-threonine and non-natural L- $\beta$ hydroxy- $\alpha$-amino acids to produce glycine and the corresponding aldehydes. The aldol addition reactions catalyzed by LTAs have great biotechnological potential for asymmetric carbon-carbon bond formation toward amino acids (Figure 1) (Fesko and Gruber-Khadjawi, 2013). The products of such reaction, $\beta$-hydroxy- $\alpha$-amino acids, are important building blocks for many complex natural products and pharmaceuticals (Breuer et al., 2004; Baltz et al., 2005; Panke and Wubbolts, 2005; Goldstein, 2006). LTAs show high stereospecificity at the $\alpha$-carbon, thus strictly only Lproducts are formed. This makes LTA a promising candidate for the stereoselective asymmetric synthesis of unnatural L-amino acids (Dückers et al., 2010; Franz and Stewart, 2014). LTAs are ubiquitous in nature and were found in bacteria, fungi and in mammalian species. Around 5,000 sequences annotated as LTA can be currently found in databases (e.g., NCBI, Swiss-Prot). However, only several genes have been subjected to structural, mechanistic, and biochemical studies (Fesko, 2016). These studies allowed scientists to elucidate key functional residues in LTAs and draw general conclusions on the mechanism of catalysis involved (Kielkopf and Burley, 2002; di Salvo et al., 2014; Qin et al., 2014). 


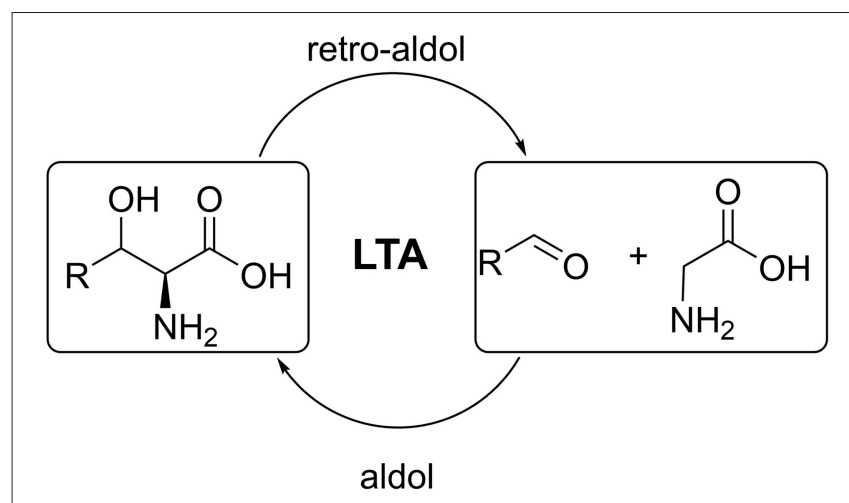

FIGURE 1 | Retro-aldol and aldol reactions catalyzed by L-threonine aldolases.

LTAs require pyridoxal- $5^{\prime}$-phosphate (PLP) as cofactor, which is covalently bonded to the apo-enzyme via the active site lysine residue. In the aldol addition reaction, an amino acid donor substrate substitutes lysine to form an external aldimine with PLP. The $\mathrm{C}_{\alpha}$-proton of the donor is then abstracted to form a carbanion, which is stabilized by delocalization in the aromatic moiety of the PLP-ring through formation of a quinonoid complex (Figure 2). The cofactor's ability to stabilize a carbanion is determined by a complex network of the PLP-surrounding residues (Fesko et al., 2018). Next, an aldehyde substrate enters from the re-side of the PLP ring to form a $\mathrm{C}_{\alpha}-\mathrm{C}_{\beta}$ bond via an aldol addition mechanism. Subsequent to the protonation of the $\mathrm{C}_{\beta}$-oxygen, an L- $\beta$-hydroxy- $\alpha$-amino acid product is released (Figure 2). The stereoselectivity at the $\mathrm{C}_{\alpha}$ of the product is stringently controlled by the enzyme, whereas the selectivity at the $\mathrm{C}_{\beta}$ bearing the hydroxyl group is often moderate and depends on the nature of substrate used (Dückers et al., 2010).

In spite of the promising opportunities to use LTAs in the biocatalytic production of non-natural amino acids, their broad application has been hindered by often moderate yields and low diastereoselectivities obtained in the aldol reaction. Thus, several directed evolution studies have been conducted to improve the stability, substrate specificity and stereoselectivity of LTAs (Franz and Stewart, 2014; Fesko, 2016). Interestingly, none of these attempts led to a variant with a significantly increased catalytic activity and diastereoselectivity. Thus, reaction engineering or rational design of enzymes, ideally in combination, might be a useful strategy for the improvement of LTA-catalyzed reactions. As suggested before, rapid epimerization of syn- and anti-isomers, leading to the fast equilibration and thus low diastereoselectivity, can be governed by appropriate protein engineering focusing on the most relevant catalytic reaction steps (Fesko et al., 2008; Franz and Stewart, 2014). Thus, understanding the detailed mechanistic features and role of the active site residue is of paramount importance for the successful rational design of LTAs.

To find catalytically important residues, a multiple sequence alignment of LTA sequences was performed recently (Giger et al., 2012). Further, the residues, which are important for the reaction specificity were identified by structure-sequence comparison of the enzymes belonging to the fold type I of PLP-dependent enzymes with different reaction specificities (Fesko et al., 2018). These studies allowed identifying catalytic core residues conserved within LTAs. Interestingly, the functional characterization of the mutants produced in previous mutagenesis studies, as well as the screening of the LTAs variants derived from directed evolution was mainly done in the retro-aldol direction with the natural substrate L-threonine (Giger et al., 2012; Bulut et al., 2015). Clearly, in view of the applications, the effect of mutations on the aldol addition to synthesize structurally different $\beta$-hydroxy- $\alpha$-amino acids is far more relevant. In our current study, we have used L-threonine aldolase from Aeromonas jandaei (LTAaj) with known broad donor specificity (Fesko et al., 2010), to evaluate the impact of mutations of active site residues on the catalytic efficiency in the aldol addition direction, the diastereoselectivity, and the donor specificity. The variants were constructed, recombinantly overexpressed, purified to homogeneity, and tested as catalysts for the aldol addition of glycine, D-alanine, or D-serine to benzaldehyde as the model reaction. The contribution of mutations on the conversion in the aldol addition reaction is compared with their impact on the activity in the retro-aldol reaction.

\section{MATERIALS AND METHODS}

\section{Chemicals and Solvents}

All chemicals were purchased from Sigma Aldrich, unless stated otherwise. All enzymes for the genetic work were purchased from ThermoFisher Scientific. The expression vector pEamTA was produced as stated before (Reisinger et al., 2007). The Escherichia coli strain BL21(DE3) was obtained from BioLabs (New England). Analytical HPLC was carried out with an Agilent 1,200 HPLC-MS system equipped with a 6,120 quadrupol mass spectrometer. UV-vis scans and single wavelength kinetics were measured on a Perkin Elmer Lambda 2 spectrophotometer.

\section{Cloning of LTAaj and Site-Directed Mutagenesis}

The wild-type LTAaj (for sequence and alignment with PDB:3WGB template see Supplementary Information) was cloned in pEamTA vector with a C-terminal His-tag as previously described (Fesko et al., 2015). LTAaj mutants were generated by site-directed mutagenesis according to Agilent's QuikChange II protocol using PfuUltra High-Fidelity DNA Polymerase (Agilent Technologies). The pEamTA-LTAaj plasmid was used as the template. Primers were ordered at Integrated DNA Technologies. PCR was carried out under the following conditions: $50 \mu \mathrm{L}$ total volume, $200 \mu \mathrm{M}$ of each dNTP, $0.2 \mu \mathrm{M}$ of each primer, $5 \mathrm{ng}$ of template plasmid DNA, and $2.5 \mathrm{U}$ of PfuUltra HighFidelity DNA polymerase. Cycling conditions were as follows: initial denaturation at $95^{\circ} \mathrm{C}$ for $2 \mathrm{~min}$, followed by 21 cycles of denaturation at $95^{\circ} \mathrm{C}$ for $30 \mathrm{~s}$, annealing at $55^{\circ} \mathrm{C}$ for $60 \mathrm{~s}$, extension at $68^{\circ} \mathrm{C}$ for $8 \mathrm{~min}$. Amplification was controlled by electrophoresis of $10 \mu \mathrm{L}$ of the PCR reaction on an agarose gel. After the digestion of parental non-mutated methylated plasmid DNA with DpnI at $37^{\circ} \mathrm{C}$ for $1 \mathrm{~h}$, the samples were desalted 


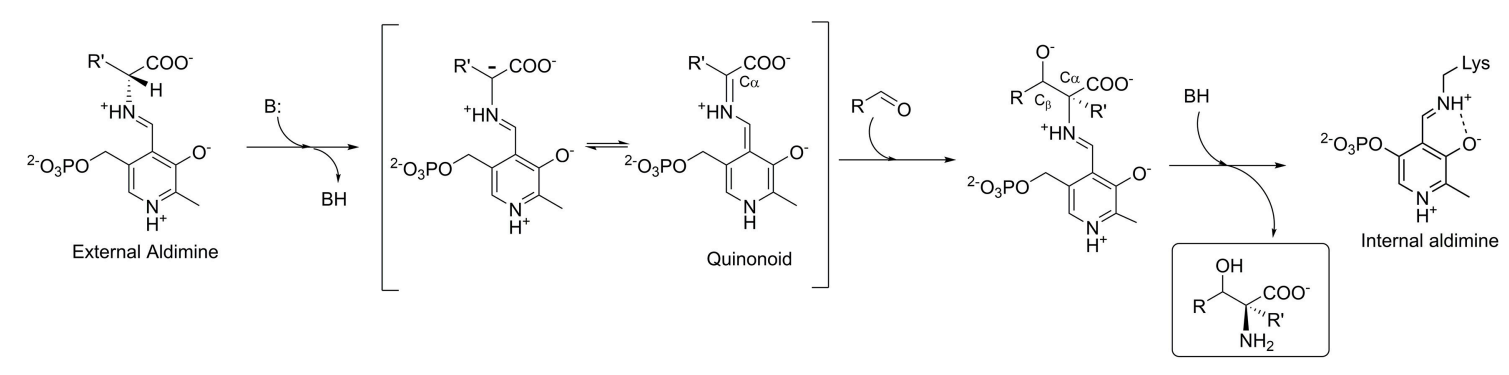

FIGURE 2 | Mechanism of the aldol addition to synthesize L- $\beta$-hydroxy- $\alpha$-amino acids catalyzed by L-threonine aldolase.

and electro-competent Escherichia coli BL21(DE3) cells were transformed with the resulting nicked vector DNA containing the desired mutations. The introduction of mutations was confirmed by sequencing analysis (LGC genomics).

\section{Protein Expression and Purification}

The constructs pEamTA-LTAaj-mut contained the tac promoter and the LacI repressor, which control the protein expression level. $300 \mathrm{~mL} 2 \mathrm{xYT}$ medium (in a $2 \mathrm{~L}$ flask) containing ampicillin $(50 \mu \mathrm{g} / \mathrm{mL})$ was inoculated with $5 \mathrm{~mL}$ of an $E$. coli overnight culture. Cells were grown at $37^{\circ} \mathrm{C}$ to an $\mathrm{OD}_{600}$ of $0.6-0.8$. Protein expression was induced by the addition of $1 \mathrm{mM}$ IPTG and the culture was allowed to grow overnight at $20^{\circ} \mathrm{C}$. The biomass of the bacterial cultures was harvested by centrifugation at $4500 \mathrm{x}$ g for $10 \mathrm{~min}$ at $4{ }^{\circ} \mathrm{C}$. The cell pellets were re-suspended in sodium phosphate buffer $(0.1 \mathrm{M}, \mathrm{pH} 7.4)$ and disrupted by ultrasonic treatment for $7 \mathrm{~min}$. The crude lysate was cleared by centrifugation at 20,000 $\mathrm{x}$ for $1 \mathrm{~h}$ at $4^{\circ} \mathrm{C}$ and subjected to further purification. Lysates were loaded onto a Ni-NTA Superflow resin (Qiagen), washed with sodium phosphate buffer $(50 \mathrm{mM}$, $\mathrm{pH} 7.4)$ containing imidazole $(5 \mathrm{mM})$ and $\mathrm{NaCl}(0.3 \mathrm{M})$ and subsequently eluted with imidazole $(0.3 \mathrm{M})$ in sodium phosphate buffer $(50 \mathrm{mM}, \mathrm{pH} 7.4)$. To remove the imidazole, the pooled and concentrated protein fractions were loaded on a Sephadex desalting column PD-10 (GE Healthcare) and eluted with sodium phosphate buffer $(50 \mathrm{mM}, \mathrm{pH} 7.4)$ containing $0.1 \mathrm{mM}$ PLP. The purified proteins were used for the activity measurements and biocatalytic transformations.

\section{Enzyme Activity Assay}

The activity of the LTAaj mutants was verified by monitoring the formation of benzaldehyde upon cleavage of DL-syn$\beta$-phenylserine $(30 \mathrm{mM})$ or $\mathrm{L}$ - $\alpha$-methyl- $\beta$-phenylserine $(55: 45$ syn:anti mixture; $30 \mathrm{mM})$ at $279 \mathrm{~nm}\left(\varepsilon=1.4 \times 10^{3} \mathrm{M}^{-1} \mathrm{~cm}^{-1}\right)$. The kinetic assays were carried out at $25^{\circ} \mathrm{C}$ in sodium phosphate buffer $(50 \mathrm{mM}, \mathrm{pH}$ 8) containing PLP $(50 \mu \mathrm{M})$ and LTA (10$50 \mu \mathrm{M})$. One activity unit $(\mathrm{U})$ is defined as the amount of enzyme that catalyzes the formation of $1 \mu \mathrm{mol}$ of benzaldehyde per minute under these conditions. Controls without the addition of TAs were carried out under the same conditions.

\section{Spectroscopic Analysis of LTAaj Variants}

The spectral scanning of purified LTAaj and mutants was performed in $1 \mathrm{~mL}$ sodium phosphate buffer $(50 \mathrm{mM}, \mathrm{pH} 8.0$ ) with LTA $(50 \mu \mathrm{M})$ in a $1 \mathrm{~cm}$ light path cuvette at the wavelength range of $300-550 \mathrm{~nm}$ at $22^{\circ} \mathrm{C}$. The formation of an external aldimine $(\lambda=420 \mathrm{~nm})$ and quinonoid intermediate $(\lambda=$ $495 \mathrm{~nm})$ was monitored after addition of a donor substrate $(0.1 \mathrm{M}$ final concentration).

\section{Chromatographic Analyses}

For substrate and product quantification by HPLC, reference DL-syn- $\beta$-phenylserine and L- $\alpha$-methyl- $\beta$-phenylserine were measured in different concentrations $(0.05-2.5 \mathrm{mM})$ to calculate standard curves for each compound. Concentrations were calculated using linear interpolation.

The HPLC-UV with pre-column derivatization was performed on an Agilent 1,200 Series HPLC system for e.e. and d.e. determination. The reaction was first quenched by diluting 1:50 with NTBB buffer $\left(0.1 \mathrm{M}\right.$ of $\left.\mathrm{Na}_{2} \mathrm{~B}_{4} \mathrm{O}_{7}, \mathrm{pH} 10.5\right)$, and the samples were treated with ortho-phthaldialdehyde/ $\mathrm{N}$ acetyl-L-cysteine (OPA/NAC). The OPA/NAC reagent was obtained by dissolving of $15 \mathrm{mg}$ of NAC in $300 \mu \mathrm{L}$ of distilled water and $300 \mu \mathrm{L}$ of NTBB, and then $10 \mathrm{mg}$ of OPA in $400 \mu \mathrm{L}$ of $\mathrm{MeOH}$ was added. A freshly prepared solution was always used. $5 \mu \mathrm{L}$ of OPA/NAC reagent was mixed with $1 \mu \mathrm{L}$ of diluted reaction solution for 5 or $15 \mathrm{~min}$ (for $\alpha$-quaternary products) in the HPLC system before injection. The molar ratio of OPA and the total of amino acids was maintained at 3.5: 1. Detection of the analytes was accomplished with a diode array detector at a wavelength of $\lambda=340 \mathrm{~nm}$. The separations were carried out on an EC 150/3 Nucleodur ${ }^{\circledR}$ C18 Gravity column $(150 \times 3.0 \mathrm{~mm}$, $3.0 \mu \mathrm{m}$; Macherey-Nagel, Düren, Germany). The mobile phases were $85 \%$ potassium phosphate buffer $(20 \mathrm{mM}, \mathrm{pH} 6.8)$ and $15 \%$ acetonitrile (ACN) isocratic flow at $2.5 \mathrm{~mL} / \mathrm{min}$.

For HPLC-MS general monitoring of the reactions, eluent mixtures consisting of methanol, and water containing 0.01 vol\% formic acid as additive were used. UV $(210 \mathrm{~nm})$ and ESI-MS detection, typically in positive mode, was used to identify the compounds. Following settings of the Agilent 6,120 MSD were applied: drying gas: $\mathrm{N}_{2}, 10.5 \mathrm{~L} / \mathrm{min}$; drying gas temperature: $350^{\circ} \mathrm{C}$; nebulizer pressure: 35 psi; capillary voltage: 3,000 V; mode: negative; scan parameters: mass range: 100-450, fragmentor: $30 \mathrm{~V}$, gain: 1.0, threshold: 150, step size: 0.10 . The separation of the analytes was carried out using a Poroshell ${ }^{\circledR} 120 \mathrm{EC}-\mathrm{C} 18,3.0 \times 100 \mathrm{~mm}, 2.7 \mu \mathrm{m}$ (Agilent, Vienna, Austria) reversed-phase column. Samples were either dissolved 
in methanol and any insoluble particles were removed prior to analysis by centrifugation or filtration through $0.2 \mu \mathrm{m}$ GHP Acrodic ${ }^{\circledR} 13 \mathrm{~mm}$ syringe filters (PN 4,567, Pall Corporation, Ann Arbor, USA). A stepwise gradient was used: $0.0 \mathrm{~min}: 98 \%$ water/ $0.1 \% \mathrm{HCOOH}$ and $2 \% \mathrm{CH}_{3} \mathrm{OH}$, linear gradient to $100 \% \mathrm{CH}_{3} \mathrm{OH}$ in $6 \mathrm{~min}, 6.0-8.0 \mathrm{~min} 100 \% \mathrm{CH}_{3} \mathrm{OH} ; 0.7 \mathrm{~mL} / \mathrm{min}, 30^{\circ} \mathrm{C}$.

\section{General Procedure for the Synthesis of L- $\beta$-Phenylserine $\mathbf{3 a}$}

The enzymatic transformations were performed in $1 \mathrm{~mL}$ reaction volume in sodium phosphate buffer $(50 \mathrm{mM}, \mathrm{pH} 8.0)$, containing PLP $(50 \mu \mathrm{M})$, DMSO $(10 \%, \mathrm{v} / \mathrm{v})$, benzaldehyde $(50 \mathrm{mM})$ and glycine $(0.5 \mathrm{M})$. Transformations were performed at $30^{\circ} \mathrm{C}$ with $0.5 \mathrm{U}$ (based on phenylserine cleavage activity) of protein. To stop the reaction, $50 \mu \mathrm{L}$ of the reaction mixture was diluted in $950 \mu \mathrm{L}$ sodium tetraborate buffer $(0.1 \mathrm{M}, \mathrm{pH} 10.5)$ and used for the determination of conversion by RP-HPLC after a pre-column derivatization with OPA/NAC.

$L$ - $\beta$-phenylserine $3 \mathrm{a}: \mathrm{t}_{\mathrm{L}-\text { syn }}=4.2 \mathrm{~min}, \mathrm{t}_{\mathrm{L}-\text { anti }}=7.5 \mathrm{~min}$.

L- $\beta$-(3-nitro)-phenylserine 4a: $\mathrm{t}_{\mathrm{L}-\mathrm{syn}}=6.7 \mathrm{~min}, \mathrm{t}_{\mathrm{L}-\mathrm{anti}}=$ $10.1 \mathrm{~min}$.

\section{General Procedure for the Synthesis of L- $\alpha$-Alkyl- $\beta$-Phenylserine 3b-d, 4b-g}

The enzymatic transformations were performed in $1 \mathrm{~mL}$ reaction volume in sodium phosphate buffer $(50 \mathrm{mM}, \mathrm{pH} 8.0)$, containing PLP $(50 \mu \mathrm{M})$, DMSO $(10 \%, \mathrm{v} / \mathrm{v}), 50 \mathrm{mM}$ of benzaldehyde or 3-nitro-benzaldehyde and $0.5 \mathrm{M}$ of $\mathrm{D}$-amino acid donor (D-alanine, D-serine, D-aminobutanoic acid, D-valine, Dnorvaline). Transformations were performed at $25^{\circ} \mathrm{C}$ with $10 \mathrm{U}$ (based on phenylserine cleavage activity) of protein. To stop the reaction, $50 \mu \mathrm{L}$ of the reaction mixture was diluted in $450 \mu \mathrm{L}$ of $50 / 50 \mathrm{methanol} /$ formic acid $0.01 \%$ and used for the HPLCMS analysis.

$L-\alpha$-methyl- $\beta$-phenylserine $3 \mathbf{b}: \mathrm{t}_{\mathrm{L}-\text { anti }}=2.7 \mathrm{~min}, \mathrm{t}_{\mathrm{L}-\mathrm{syn}}=$ $4.1 \mathrm{~min} ;[\mathrm{M}+1]^{+} 195.9$

L- $\alpha$-hydroxymethyl- $\beta$-phenylserine $3 \mathrm{c}: \mathrm{t}_{\mathrm{L}-\text { anti }}=1.3 \mathrm{~min}$, $\mathrm{t}_{\mathrm{L}-\text { syn }}=1.8 \mathrm{~min} ;[\mathrm{M}+1]^{+} 212.1$

$L$ - $\alpha$-ethyl- $\beta$-phenylserine $3 \mathrm{~d}: \mathrm{t}_{\mathrm{L}-\mathrm{anti}}=2.1 \mathrm{~min}, \mathrm{t}_{\mathrm{L}-\mathrm{syn}}=2.3 \mathrm{~min}$; $[\mathrm{M}+1]^{+} 210.1$

L- $\alpha$-methyl- $\beta$-(3-nitro)-phenylserine $4 \mathbf{b}: \mathrm{t}_{\mathrm{L}-\text { anti }}=3.1 \mathrm{~min}$, $\mathrm{t}_{\mathrm{L}-\mathrm{syn}}=4.4 \mathrm{~min} ;[\mathrm{M}+1]^{+} 241.2$

L- $\alpha$-hydroxymethyl- $\beta$-(3-nitro)-phenylserine $\quad 4 \mathrm{c}$ : $\mathrm{t}_{\mathrm{L}-\text { anti }}=$ $1.6 \mathrm{~min}, \mathrm{t}_{\mathrm{L}-\text { syn }}=2.1 \mathrm{~min} ;[\mathrm{M}+1]^{+} 257.2$

L- $\alpha$-ethyl- $\beta$-(3-nitro)-phenylserine $4 \mathrm{~d}: \mathrm{t}_{\mathrm{L}-\text { anti }}=2.3 \mathrm{~min}$, $\mathrm{t}_{\mathrm{L}-\text { syn }}=2.5 \mathrm{~min} ;[\mathrm{M}+1]^{+} 255.0$

$L$ - $\alpha$-propyl- $\beta$-(3-nitro)-phenylserine $4 \mathbf{f}$ : $\mathrm{t}_{\mathrm{L}-\text { anti }}=2.6 \mathrm{~min}, \mathrm{t}_{\mathrm{L}-\text { syn }}$ $=2.8 \mathrm{~min} ;[\mathrm{M}+1]^{+} 269.2$

L- $\alpha$-(2-hydroxyethyl)- $\beta$-(3-nitro)-phenylserine $\quad 4 \mathrm{~g}: \mathrm{t}_{\mathrm{L}-\text { anti }}=$ $2.1 \mathrm{~min}, \mathrm{t}_{\mathrm{L}-\text { syn }}=2.2 \mathrm{~min} ;[\mathrm{M}+1]^{+} 271.2$

\section{RESULTS}

The active site residues, which are located within $5 \AA$ from PLP-Glycine complex in LTAaj (reference PDB: 3WGB), were selected for the site-directed mutagenesis to test their influence

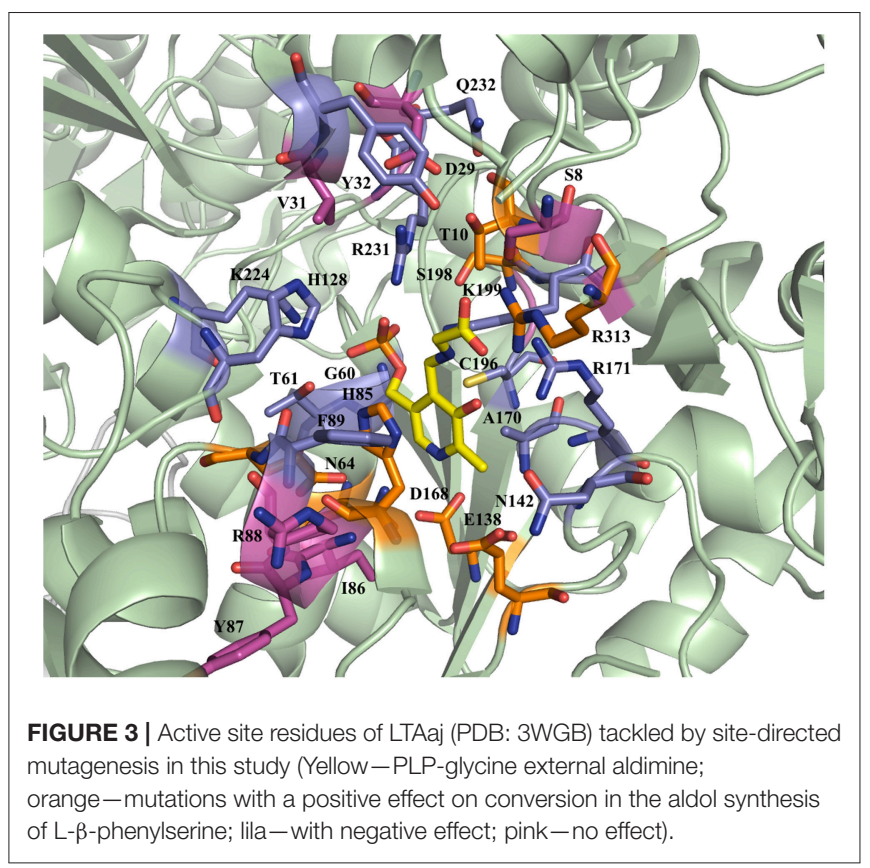

on the outcome in aldol reactions (Figure 3). LTAs accept a wide range of aliphatic and aromatic aldehydes as an electrophilic substrate, whereas glycine is accepted as the only nucleophile donor by most of the known LTAs (Steinreiber et al., 2007a,b; Franz and Stewart, 2014). LTAaj is a unique enzyme with broad donor specificity, accepting other small-sized D-amino acids as donors (Fesko et al., 2010; Blesl et al., 2018). The aldol additions of benzaldehyde (1a) to amino acid donors [glycine (2a), Dalanine (2b), D-serine (2c), and D-aminobutanoic acid (2d)] to produce L- $\beta$-phenylserine (3a) and L- $\alpha$-alkyl- $\beta$-phenylserine $3 \mathbf{b}$ d, respectively, were used as model reactions in this study to compare the properties of the LTAaj mutant variants (Figure 4). The best mutants were also tested with 3-nitro-benzaldehyde (1b) substrate as evidence that obtained features can be extended to reactions with other aldehydes.

\section{Favorable Mutations for the Synthesis of L- $\beta$-Phenylserine (3a)}

According to the phylogenetic analysis of LTA sequences, LTAs can be grouped into two major functional families-L-allo-TA and L-low specificity TA, which correlates with their specificity at $\mathrm{C}_{\beta}$ of L-threonine (Liu et al., 2015; Fesko et al., 2018). The sequence similarity is low between functional families and only a few conserved residues were found in all LTA sequences (G60, T61, N64, H85, E90, E138, D168, R171, and R313 in LTAaj). It is not surprising, that their mutation led to a significant loss of activity in the cleavage of L-threonine and L- $\beta$ phenylserine (Fesko et al., 2018). In this study, we have tested the performance of these and other active site mutants in the aldol addition reactions. Interestingly, the variants N64I, H85F, E90A, E138A, D168S, C196T, G200S, R231A, R313F with a significantly decreased retro-aldol activity catalyse the formation of $\mathbf{3} \mathbf{a}$ with conversions similar or even higher than the wild type enzyme 


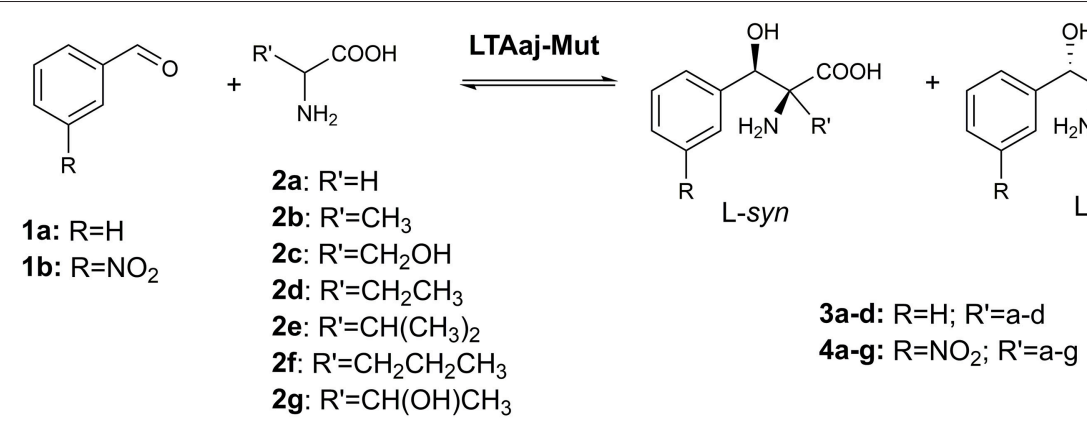

FIGURE 4 | Aldol addition of aldehyde $\mathbf{1}$ to an amino acid donor $\mathbf{2}$ catalyzed by the LTAaj variants.

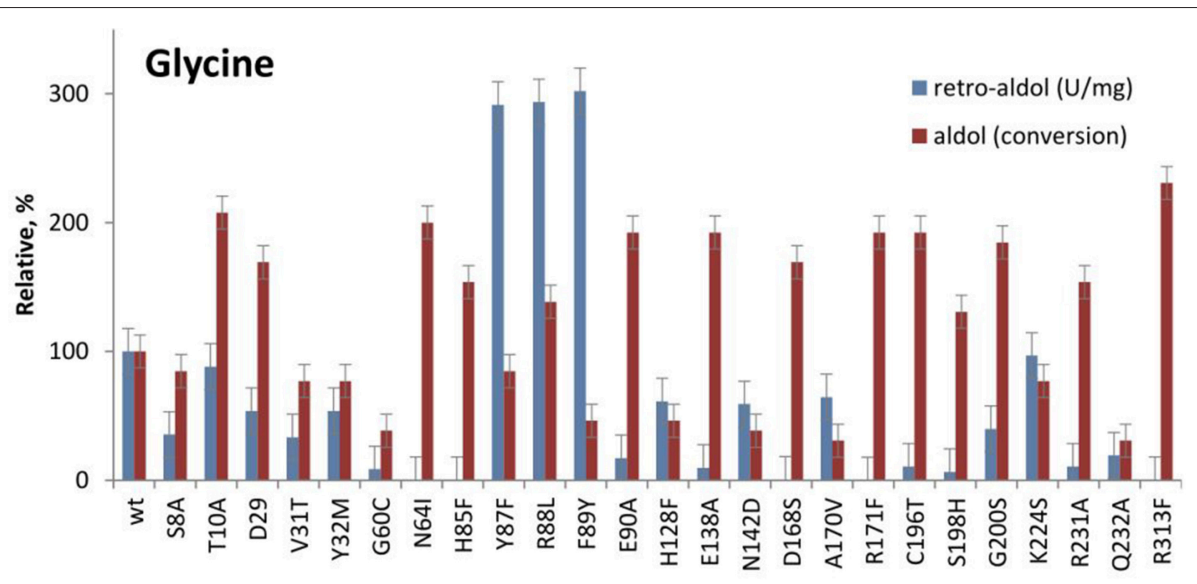

FIGURE 5 | Relative catalytic activity in the retro-aldol cleavage and conversion after $24 \mathrm{~h}$ in the aldol synthesis of L- $\beta$-phenylserine catalyzed by LTAaj mutants.

although with slower rates (Figure 5, Table 1). For example, the R313F mutant with 500 fold reduced catalytic activity in the cleavage reaction, produces $3 \mathrm{a}$ with $40 \%$ conversion after $24 \mathrm{~h}$ and $70 \%$ after 5 days.

As was shown before, these conserved residues are essential to control the electrophilic strength of the PLP cofactor to act as an electron sink stabilizing the formed carbanion after $\mathrm{C}_{\alpha^{-}}$ $\mathrm{C}_{\beta}$ bond cleavage by the formation of quinonoid species of the PLP-glycine complex (Figure 2) (Fesko et al., 2018). This seems to be important for the retro-aldol reaction, but less essential in the opposite reaction-formation of the $\beta$-hydroxy- $\alpha$-amino acid. Previously, we have shown, that the rate-limiting step in the LTA catalyzed reactions is the $\mathrm{C}_{\alpha}-\mathrm{H}$ deprotonation of glycine donor (aldol direction) or protonation of the $\mathrm{C}_{\alpha}$ carbanion to form glycine (retro-aldol direction) (Figure 6) (Fesko et al., 2008). Thus, in the retro-aldol reaction, the life-time of the glycine carbanion is longer in comparison to the aldol reaction and has to be stabilized via delocalization of electron density in the PLP-ring.

The significantly higher energy barrier for the $\mathrm{C}_{\alpha}-\mathrm{H}$ protonation step in comparison to the $\mathrm{C}_{\alpha}-\mathrm{C}_{\beta}$ bond cleavage step requires a more stable carbanion in the case of retroaldol cleavage (Fesko et al., 2008). The above described catalytic residues influence carbanion stability and thus suppress the retro-aldol reaction. Due to inhibition of reverse step, in the aldol addition reaction the equilibrium is reached later leading to the accumulation of the aldol products, when an excess of a donor is applied. Similar behavior was observed earlier for D-threonine aldolases, when aldol reactions were performed at low temperatures to suppress the cleavage reaction and to obtain aldol products under kinetic control (Steinreiber et al., 2007b). However, this was not possible to achieve in LTA catalyzed reactions due to its very high retro-aldol activity and fast equilibration even at low temperatures (Gutierrez et al., 2008). Here we observed mutations with intrinsically low retroaldol activity, what allowed running the aldol reaction under kinetic control. Thus, conversion up to $60 \%$ was obtained for LTAaj variants with $\mathbf{1 a}$ and $\mathbf{2 a}$, whereas only $20 \%$ was previously reported for the wild type enzyme under standard conditions (Figure 7, Table 1) (Blesl et al., 2018).

Moreover, in previous studies high excess of LTA was usually applied for the biocatalytic aldol reaction (5-10 $\mathrm{U}$ in a $1 \mathrm{~mL}$ reaction according to different studies) (Steinreiber et al., 2007a,b; Gutierrez et al., 2008; Dückers et al., 2010). This led to faster equilibration and the thermodynamically-controlled mixtures of products (syn/anti) was obtained. In the case of "low 
TABLE 1 | The catalytic activity of the LTAaj mutants in the retro-aldol cleavage reaction of L- $\beta$-syn-phenylserine (3a) and L- $\alpha$-methyl- $\beta$-phenylserine (3b).

\begin{tabular}{|c|c|c|c|c|c|c|c|c|c|c|c|}
\hline \multirow[t]{2}{*}{ Position } & \multirow[t]{2}{*}{ Mutants } & \multicolumn{2}{|c|}{ Retro-aldol } & \multicolumn{8}{|c|}{ Aldola $^{a}$} \\
\hline & & $\begin{array}{c}3 a \\
\mathrm{U} / \mathrm{mg}\end{array}$ & $\begin{array}{c}3 \mathbf{b} \\
\mathrm{U} / \mathrm{mg}\end{array}$ & Conv.\% & d.r. & Conv.\% & d.r. & Conv.\% & d.r. & Conv.\% & d.r. \\
\hline \multirow[t]{2}{*}{ wt } & - & 93 & 1.1 & 38 & $72: 28$ & 0 & - & 0 & - & 0 & - \\
\hline & & & & $15^{b}$ & $60: 40$ & $23(52)^{b}$ & 65:35 & $8^{2}$ & 45:55 & 0 & - \\
\hline S8 & A & 32.6 & n.d. & 11 & $87: 13$ & 18 & $55: 45$ & 8 & $48: 52$ & 0 & - \\
\hline $\mathrm{T} 10$ & D & 130.3 & n.d. & 5 & 63:38 & 22 & $55: 45$ & 9 & $47: 53$ & 0 & - \\
\hline D29 & A & 49.7 & 6.2 & 22 & $67: 33$ & 21 & $55: 45$ & 4 & $50: 50$ & 4 & n.d. \\
\hline \multirow[t]{3}{*}{ V31 } & Y & 30.8 & 1.3 & 10 & $52: 48$ & 20 & $60: 40$ & 8 & $50: 50$ & n.d. & - \\
\hline & $\mathrm{R}$ & 12.1 & n.d. & 12 & $70: 30$ & 23 & $60: 40$ & 13 & $48: 52$ & n.d. & - \\
\hline & $\mathrm{T}$ & 14.1 & 1.8 & 4 & $70: 30$ & 30 & $55: 45$ & 15 & $45: 55$ & 4 & $68: 32$ \\
\hline N64 & I & 0.22 & n.d. & 39 (58) & $63: 37$ & 0 & - & 0 & - & 0 & - \\
\hline \multirow[t]{2}{*}{ H85 } & $\mathrm{F}$ & 0.2 & 0.05 & $11(21)$ & $15: 85$ & 0 & - & 0 & - & 0 & - \\
\hline & Y & 0.02 & n.d. & 17 & $55: 45$ & 0 & - & 0 & - & 0 & - \\
\hline Y87 & $\mathrm{D}$ & 271 & 1.1 & 11 & $75: 25$ & 30 & $50: 50$ & 9 & $45: 55$ & $<1$ & n.d. \\
\hline R88 & L & 273 & 1.6 & 18 & $70: 30$ & 23 & $60: 40$ & 8 & $45: 55$ & $<1$ & n.d. \\
\hline F89 & Y & 281 & n.d. & 6 & $70: 30$ & 15 & $45: 55$ & 9 & $48: 52$ & $<1$ & n.d. \\
\hline E90 & A & 16 & n.d. & 25 & $65: 35$ & 4 & $70: 30$ & 2 & $60: 40$ & 0 & - \\
\hline \multirow[t]{2}{*}{ H128 } & $\mathrm{F}$ & 57 & n.d. & 6 & $65: 35$ & 27 & $55: 45$ & 9 & $44: 56$ & $<1$ & n.d. \\
\hline & Y & 102 & 2.3 & 5 & $70: 30$ & 35 & $60: 40$ & 14 & $46: 54$ & $<1$ & n.d. \\
\hline E138 & A & 8.8 & 0.2 & 25 & $65: 35$ & 3 & $85: 15$ & 1 & $65: 35$ & $<1$ & n.d. \\
\hline K224 & S & 89.5 & n.d & 10 & $80: 20$ & 30 & 65:35 & 10 & $50: 50$ & $<1$ & n.d. \\
\hline R231 & A & 9.7 & 4.5 & 20 & $70: 30$ & 14 & $60: 40$ & 9 & $45: 55$ & $<1$ & n.d. \\
\hline Q232 & A & 18 & n.d & 4 & $60: 40$ & 13 & $58: 42$ & 6 & $50: 50$ & 4 & $67: 33$ \\
\hline R313 & $\mathrm{F}$ & 0.2 & 0 & $30(61)$ & $55: 45$ & 0 & - & 0 & - & 0 & - \\
\hline $\mathrm{H} 85 \mathrm{~F} / \mathrm{H} 128 \mathrm{~F}$ & & 4.5 & 0 & 20 & $75: 25$ & 2 & $50: 50$ & 0 & - & 0 & - \\
\hline H85F/H128Y & & 4.5 & 0 & 5 & $60: 40$ & 2 & $40: 60$ & 0 & - & 0 & - \\
\hline R231A/G200S & & 23 & n.d & 11 & $60: 40$ & 20 & $65: 35$ & 5 & $60: 40$ & $<1$ & $20: 80$ \\
\hline R231A/Y32M & & 27 & 11.1 & 20 & $80: 20$ & 17 & $60: 40$ & 7 & $50: 50$ & 8 & $45: 55$ \\
\hline R231A/Y32G & & 6.5 & n.d & 22 & $80: 20$ & 12 & $55: 45$ & 1 & $50: 50$ & 2 & $50: 50$ \\
\hline R231A/H85F & & 10 & 0 & 19 & $80: 20$ & 1 & $37: 63$ & 0 & - & 0 & - \\
\hline R231A/S198H & & 7 & n.d & 20 & $80: 20$ & 22 & $60: 40$ & 10 & $55: 45$ & 2 & $25: 75$ \\
\hline R231AV31R & & 27 & 2.1 & 5 & $60: 40$ & 18 & $55: 45$ & 3 & $60: 40$ & n.d. & - \\
\hline $\mathrm{R} 231 \mathrm{G} / \mathrm{T} 10 \mathrm{G}$ & & 5.1 & n.d & 11 & $75: 25$ & 18 & $60: 40$ & 3 & $55: 45$ & n.d. & - \\
\hline
\end{tabular}

Conversion and the diastereomeric ratio (syn:anti) after $24 \mathrm{~h}$ in the aldol addition of benzaldehyde (1a) to glycine (2a), D-alanine (2b), D-serine (2c), and D-aminobutanoic acid (2d) catalyzed by LTAaj mutants.

${ }^{a}$ Reaction conditions: $0.5 \mathrm{U}$ (for $\mathbf{2 a}$ ) or $5 \mathrm{U}$ (for $\mathbf{2 b}$-d) of enzyme, $50 \mathrm{mM}$ of $\mathbf{1 a}, 500 \mathrm{mM}$ of $\mathbf{2 a - c}, 20 \mathrm{mM} \mathrm{NaH}_{2} \mathrm{PO}_{4}$ buffer pH 8.0, $1 \mathrm{~mL}, 25^{\circ} \mathrm{C}$. Products detected by HPLC/LC-MS; e.e.L $>99 \%$.

b $10 \cup$ of wt LTAaj.

${ }^{c}$ in brackets reaction time 5 days.

n.d., not determined. 


\section{Aldol:}

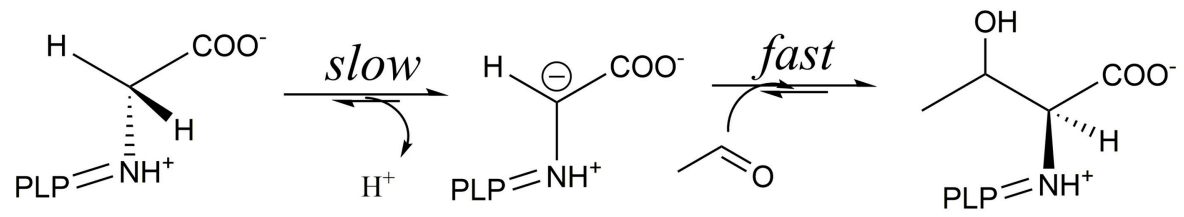

PLP-Glycine

PLP-L-threonine

\section{Retro-aldol:}

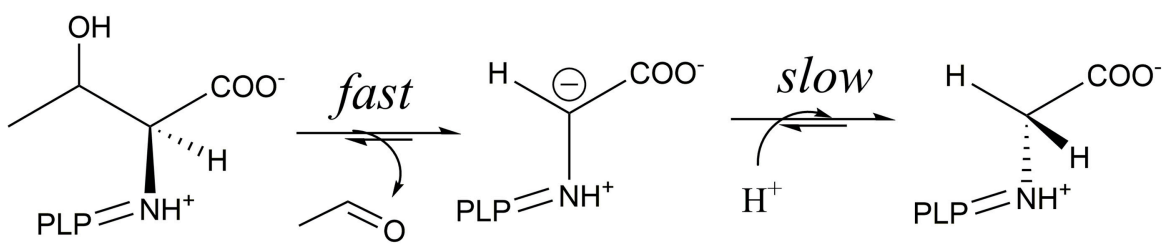

\section{PLP-L-threonine}

\section{PLP-Glycine}

FIGURE 6 | Relative rates of subsequent reaction steps in the aldol and retro-aldol reaction catalyzed by LTAaj.

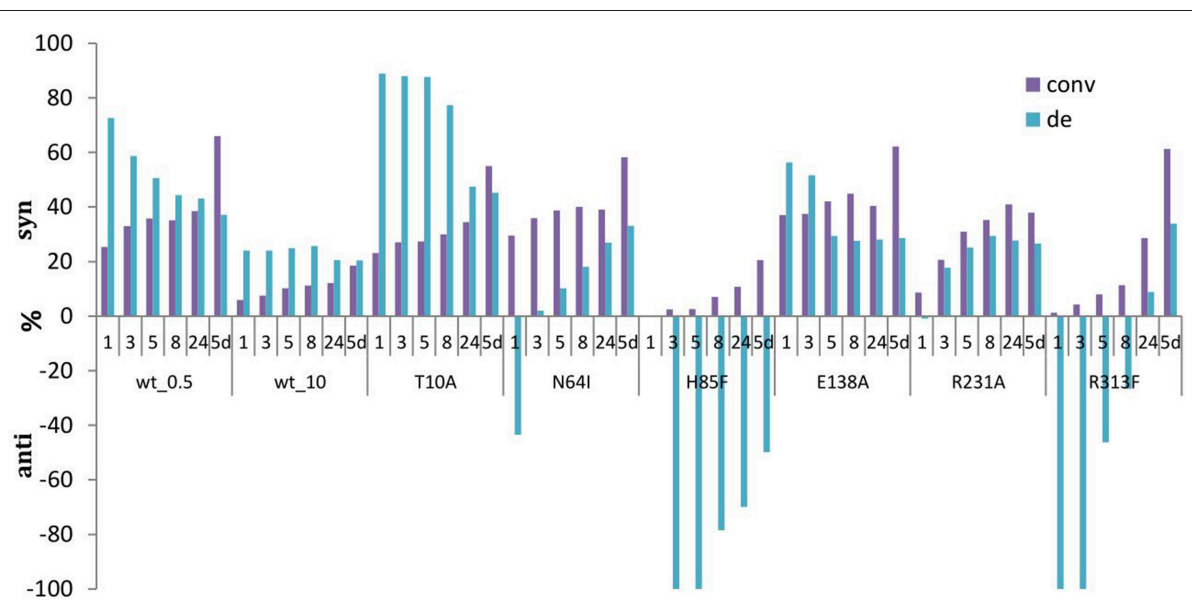

FIGURE 7 | Development of conversions and diastereoselectivities within reaction times ( $1 \mathrm{~h}-5 \mathrm{~d}$ ) in the aldol synthesis of L- $\beta$-phenylserine catalyzed by LTAaj mutants. $(0.5 \mathrm{U}$ per $1 \mathrm{~mL}$ reaction of LTAaj variants and wt_0.5, $10 \mathrm{U}$ per $1 \mathrm{ml}$ reaction of wt_10 were used in the reaction; d.e. $=(($ syn-anti)/(syn+anti) $100 \%)$.

active" mutants or reducing the amount of wild type enzyme in the reaction mixture to $0.5 \mathrm{U}$, the products can be obtained under kinetically controlled conditions, when syn-isomer (in case of L$\beta$-phenylserine) is formed faster than anti-isomer, leading to d.e. up to $80 \%$ and conversion of $20 \%$ after $5 \mathrm{~h}$ of reaction time (e.g., T10A mutant, Figure 7). Interestingly, some mutations cause the inversion of stereopreferences in the kinetically-controlled mode, thus anti-product was obtained as the major isomer for N64I, H85F, and R313F mutants. To conclude, for an efficient retro-aldol cleavage process catalyzed by LTA, the $\mathrm{C}_{\alpha}$-carbanion intermediate has to be stabilized, whereas in the aldol process this is much less important. Thus, lowering the retro-aldol activity opens the possibility to run the aldol reaction under kinetic control to reach high diastereoselectivities with good conversion.

\section{Unfavorable Mutations for the Synthesis of L- $\beta$-Phenylserine}

The active site positions, which are located in the aldehyde substrate binding pocket (Y32, F89, K224), as well as positions important for the cofactor binding (G60, N142, A170, R171, $\mathrm{R} 231)$ or participate in the $\mathrm{C}_{\beta}-\mathrm{OH}$ protonation $(\mathrm{H} 85, \mathrm{Y} 87$, 


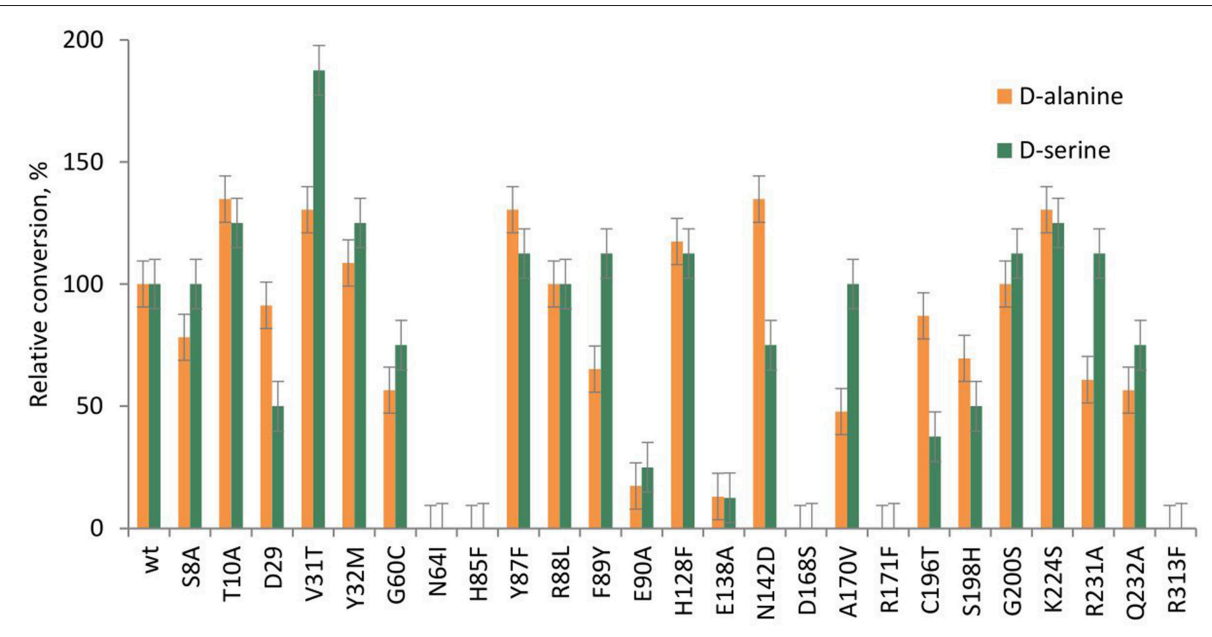

FIGURE 8 | Relative conversion in the aldol addition of benzaldehyde to D-alanine $\mathbf{2 b}$ and D-serine $\mathbf{2 c}$, catalyzed by LTAaj mutants.

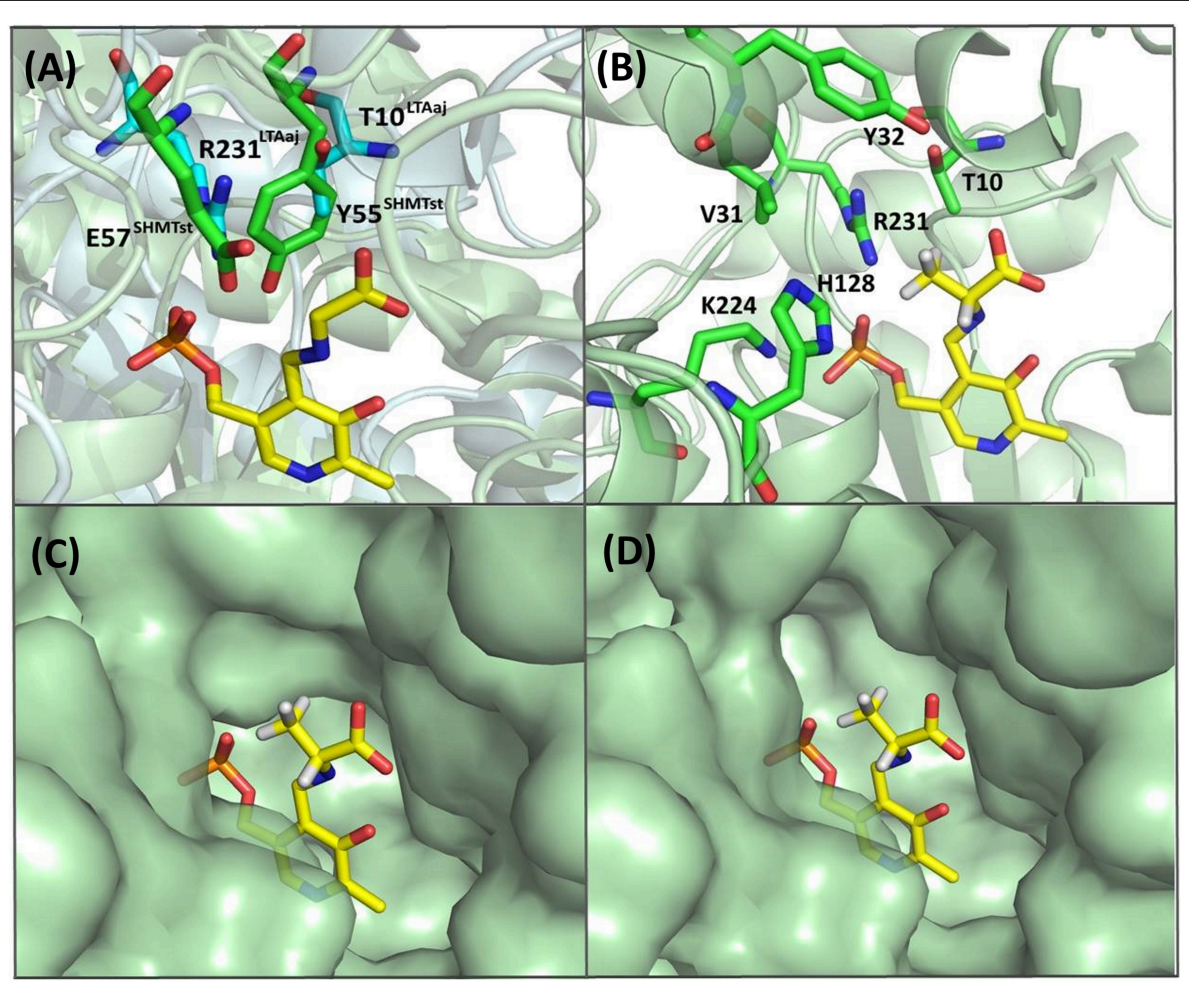

FIGURE 9 | (A) Alignment of active site residues of SHMTst (green) and LTAaj (blue); (B) LTAaj active site residues, which influence the donor specificity; (C) wild type LTAaj active site pocket; (D) LTAaj R231A active site pocket.

H128) reduce the conversion in the aldol addition reaction catalyzed by LTAaj (Figure 5, Table 1). The strongest negative impact on the aldol addition of benzaldehyde 1a to glycine 2a was observed for the mutations at residues responsible for the binding and fixation of the PLP-cofactor in the active site. For example, G60C perturbs the hydrogen bonding with the phosphate group of PLP and reduces the retroaldol activity 10 -fold, but gives only $5 \%$ conversion in the synthesis of 3a. The large cavity on the re-face of the PLP-ring is beneficial for accommodating large aliphatic and aromatic aldehydes, whereas the introduction of the polar residues (e.g., Thr, Ser, or Asn) in positions 32, 89, and 224 results in the decrease of conversion. The positions Y87 and H128 are responsible for the protonation of $\mathrm{C}_{\beta}-\mathrm{OH}$ group, as was shown previously (Qin et al., 2014). Their mutation led to significantly decreased conversions in the aldol synthesis 
TABLE 2 | Conversions and the diastereomeric ratio (syn:anti) after $24 \mathrm{~h}$ in the aldol addition of benzaldehyde (1a) to glycine (2a), D-alanine (2b), D-serine (2c), and D-aminobutanoic acid (2d) catalyzed by R231X LTAaj mutants.

\begin{tabular}{|c|c|c|c|c|c|c|c|c|c|}
\hline \multirow[t]{3}{*}{ Position } & \multirow[t]{3}{*}{ Mutants } & \multicolumn{8}{|c|}{ Aldol $^{\mathrm{a}}$} \\
\hline & & \multicolumn{2}{|c|}{$2 a$} & \multicolumn{2}{|c|}{$2 b$} & \multicolumn{2}{|c|}{$2 c$} & \multicolumn{2}{|c|}{$2 d$} \\
\hline & & Conv.\% & d.r. & Conv. \% & d.r. & Conv. \% & d.r. & Conv. \% & d.r. \\
\hline \multirow[t]{11}{*}{ R231 } & $A$ & 20 & $70: 30$ & 14 & $60: 40$ & 9 & $45: 55$ & $<1$ & n.d. \\
\hline & $\mathrm{K}$ & 15 & $60: 40$ & 18 & $60: 40$ & 7 & $55: 45$ & n.d. & - \\
\hline & $\mathrm{G}$ & 14 & $65: 35$ & 17 & $60: 40$ & 9 & $55: 45$ & 2 & $20: 80$ \\
\hline & $\mathrm{F}$ & 16 & $70: 30$ & 10 & $65: 35$ & 8 & $55: 45$ & n.d. & - \\
\hline & $\mathrm{T}$ & 14 & $65: 35$ & 14 & $63: 37$ & 9 & $55: 45$ & n.d. & - \\
\hline & C & 12 & $60: 40$ & 21 & $63: 37$ & 7 & $50: 50$ & n.d. & - \\
\hline & $\mathrm{H}$ & 14 & $60: 40$ & 23 & $60: 40$ & 10 & $50: 50$ & 3 & $50: 50$ \\
\hline & $D$ & 20 & $70: 30$ & 5 & $60: 40$ & 8 & $42: 58$ & n.d. & - \\
\hline & V & 16 & $60: 40$ & 19 & $55: 45$ & & & 3 & n.d. \\
\hline & Q & 20 & $60: 40$ & 24 & $55: 45$ & 5 & $45: 55$ & 3 & n.d. \\
\hline & $\mathrm{M}$ & 18 & $60: 40$ & 19 & $55: 45$ & & & 3 & n.d. \\
\hline
\end{tabular}

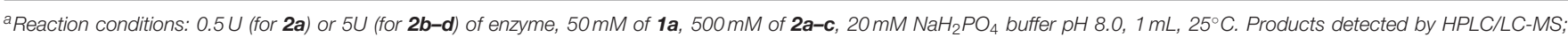
e.e.L $>99 \%$.

n.d., not determined.

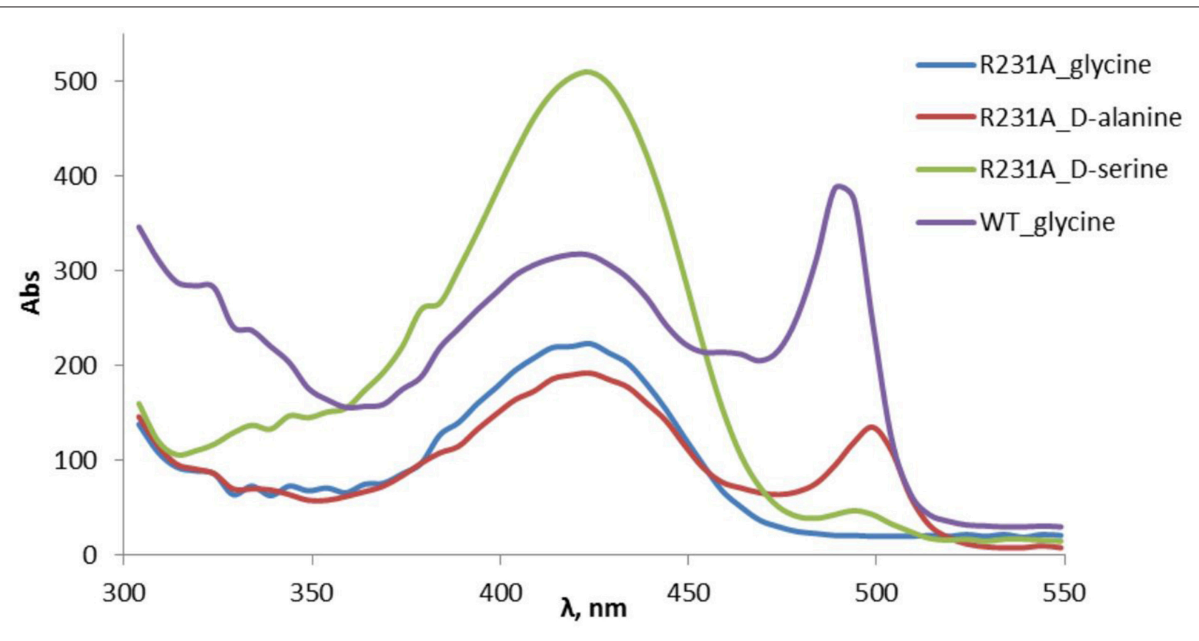

FIGURE 10 | Formation of PLP-quinonoid complex ( $\left.\lambda_{\max } \approx 495 \mathrm{~nm}\right)$ with the amino acid donor substrates in the wild type and R231A mutant of LTAaj.

of $\mathbf{3 a}$, whereas for the retro-aldol cleavage the effect was not significant.

\section{Favorable Mutations for the Synthesis of L- $\alpha$-Alkyl- $\beta$-Phenylserines}

Besides the natural donor glycine 2a, wild type LTAaj accepts also $\mathrm{D}$-alanine $\mathbf{2 b}$, and $\mathrm{D}$-serine $\mathbf{2} \mathbf{c}$ in the aldol addition reaction with aldehydes to produce highly valuable $\mathrm{L}$ - $\alpha$-quaternary- $\alpha$-amino acids (Fesko et al., 2010). In order to improve the performance of biocatalytic transformations, reaction engineering was recently performed and a wide range of L- $\alpha$-alkyl- $\beta$-hydroxy-a-amino acids were produced (Blesl et al., 2018). To further improve the donor specificity and conversions in the reactions, enzyme engineering can be additionally used. Thus, here we have investigated the influence of mutations of active site residues on the aldol synthesis of $\alpha$-alkyl- $\beta$-phenylserines (Figure 8).

Recently, serine hydroxy-methyltransferase from Streptococcus thermophiles (SHMTst) was engineered to accept D-serine as a donor in the aldol reaction with aldehydes (Hernandez et al., 2015). The mutation Y55T was found to be beneficial to introduce the novel donor specificity presumably due to the generated space which allows to accommodate the (hydroxy)methyl group of the D-serine donor. Additionally, the hydroxy-group of T55 stabilizes the donor in the proper orientation for $\mathrm{C}_{\alpha}-\mathrm{H}$ proton abstraction via hydrogen bonding. In LTAaj T10 occupies the same space as Y55 in SHMTst (Figure 9A). Indeed, the T10A LTAaj mutant increased the 
conversion by 1.5 fold in the aldol addition of $\mathbf{1 a}$ to $\mathbf{2 b}$ to produce $\mathbf{3 b}$ with up to $70 \%$ conversion (Figure 8, Table 1). Besides T10, we have found positions D29, V31, Y32, H128, R231, and K224, which interact with the side-chain of an amino-acid donor, to have an impact on the donor specificity. The mutations V31T, $\mathrm{Y} 32 \mathrm{M}$, and $\mathrm{K} 224 \mathrm{~S}$ increased the substrate binding pocket to accommodate the side chain of a donor and thus improved the conversion in the aldol reaction with $\mathbf{2 b}$ and $\mathbf{2 c}$ (Figure 9B).

The change of arginine at position 231 to a smaller residue would create even more space and one would expect increased donor specificity for R231X mutants (Figures 9C,D). We performed the site-saturation mutagenesis at R231 in order to find an appropriate residue for this position and tested the variant for the synthesis of $\mathbf{3 b}, \mathbf{3} \mathbf{c}$, and $\mathbf{3 d}$. The substitution to the positively charged amino acids (e.g., Lys, Gln) did not significantly influence the conversion. However, small aliphatic residues or residues bearing a negative charge decreased the conversion despite enlarged space upon mutation in comparison to the wild type (Table 2). This might be due to the important role of the residue $\mathrm{R} 231$ in the catalytic mechanism. It is a conserved residue among L-allo specific threonine aldolases, which participates in the hydrogen bonding with the phosphate group of PLP, as well as maintains the pKa of Schiff-base forming lysine K199 and acts as the general acid/base in the external aldimine formation (Fesko et al., 2018). Moreover, the spectrophotometric analysis showed that R231A mutation hinders the formation of the quinonoid complex with glycine (Figure 10) and, consequently, reduces the natural retro-aldol activity toward L- $\beta$-phenylserine by 10 fold. This confirms that R231 is an important catalytic residue, which participates in maintaining the hydrogen network in the active site for donor stabilization.

Interestingly, the quinonoid species were formed in the R231A mutant with non-natural donors, e.g., $2 \mathbf{b}$ and 2c (Figure 10). This might be due to the divergent mechanism of the fixation of the donors in the active site for $\mathrm{C}_{\alpha}-\mathrm{H}$ abstraction and carbanion stabilization. Indeed, different mutations improve the conversion in the aldol reactions with different donors. Thus, for donor $\mathbf{2 b}$, the best conversion was obtained with the T10A mutant (Table 1). The conversion with $2 \mathrm{c}$ donor was increased upon mutation to V31T, where T31 might stabilize the donor in a proper orientation via hydrogen bonding with the hydroxy group of serine substrate. For 2d, the double mutant R231A/Y32M increased the conversion from 0.5 to $8 \%$, presumably due to improved hydrogen stabilization between the side chain of $\mathbf{2 d}$ and M32. Further, H128Y increases the conversion in the aldol reaction with both $\mathbf{2 b}$ and $\mathbf{2 c}$ by providing a hydrophobic environment for the side chain of an amino acid product. Interestingly, $\mathrm{H} 128$ participates in the $\mathrm{C}_{\beta}-\mathrm{OH}$ protonation in the reaction with natural donor glycine 2a (Qin et al., 2014; Fesko et al., 2018), therefore conversion toward $\mathbf{3} \mathbf{a}$ is reduced for $\mathrm{H} 128 \mathrm{~F}$ and H128Y mutants (Table 1). In the case of nonnatural donors $\mathbf{2 b}-\mathbf{2} \mathbf{d}$, the reactions were not affected by the $\mathrm{H} 128 \mathrm{~F}$ mutation, which indicates that other residue protonate $\mathrm{C}_{\beta}-\mathrm{O}^{-}$toward $\alpha$-quaternary amino acids.

As was shown before, aldehyde 1a is not optimal substrate for LTA-catalyzed reactions and higher conversions can be obtained
TABLE $\mathbf{3}$ | Conversions in the reaction of 3-nitro-benzaldehyde (1) with D-amino acid donors $\mathbf{2} \mathbf{a}-\mathbf{g}$ to produce $\mathbf{4}$ catalyzed by LTAaj mutants.

\begin{tabular}{|c|c|c|c|c|}
\hline Mutant & Acceptor & Donor & conv., ${ }^{\star} \%$ & d.r. \\
\hline \multirow[t]{4}{*}{ wt } & $1 b$ & $2 a$ & $>95$ & $80: 20$ \\
\hline & & $2 b$ & 60 & $65: 35$ \\
\hline & & 2c & 15 & $40: 60$ \\
\hline & & $2 d$ & 2 & $50: 50$ \\
\hline \multirow[t]{3}{*}{ T10A } & $1 b$ & $2 a$ & $>95$ & $80: 20$ \\
\hline & & $2 b$ & 80 & $68: 32$ \\
\hline & & $2 d$ & 7 & $70: 30$ \\
\hline V31T & $1 b$ & $2 d$ & 26 & $58: 42$ \\
\hline N64I & $1 b$ & $2 a$ & 86 & $75: 25$ \\
\hline H85F & $1 b$ & $2 a$ & 51 & $65: 35$ \\
\hline R231Q & $1 b$ & $2 d$ & 19 & $65: 35$ \\
\hline R313F & $1 b$ & $2 a$ & $>95$ & $70: 30$ \\
\hline \multirow[t]{5}{*}{ R231AYY32M } & $1 b$ & 2c & 15 & $50: 50$ \\
\hline & & $2 d$ & 33 & 63:38 \\
\hline & & $2 e$ & 0 & - \\
\hline & & $2 f$ & 2 & $58: 42$ \\
\hline & & $2 \mathrm{~g}$ & 1 & $>95: 5$ \\
\hline
\end{tabular}

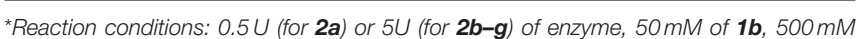
of 2a-g, $10 \% \mathrm{v} / \mathrm{v}$ DMSO, $20 \mathrm{mM} \mathrm{NaH}_{2} \mathrm{PO}_{4}$ buffer $\mathrm{pH} 8.0,1 \mathrm{~mL}, 25^{\circ} \mathrm{C}$. Products detected by HPLC-MS; e.e.L > 99\%; $d: r=$ syn:anti.

with the aromatic substrates bearing electron-withdrawing groups (Fesko et al., 2015; Blesl et al., 2018). Thus, we have applied 3-nitrobenzaldehyde (1b) as substrate to test other bulky donors with the mutant variants of LTAaj. Consequently, the conversion with the donor $\mathbf{2 d}$ was improved from $2 \%$ for the wild type to 33\% for the R231A/Y32M mutant (Table 3). Further, the double mutant accepts also $\mathbf{2} \mathbf{f}$ and $\mathbf{2} \mathbf{g}$ as donors, albeit with low efficiency, which were not accepted by the wild type. The decrease of conversion with an increasing donor's side chain can be enforced due to its interaction with the phosphate group of PLP and destabilization of the overall enzyme-substrate complex. Thus, more rational active site design with simulation studies is beneficial for further engineering of donor specificity of LTAaj. To conclude, in order to get other D-donors accepted, the active site should be designed toward a specific target to enlarge the pocket, respectively, and to fix a donor in the optimal position for $\mathrm{C}_{\alpha}-\mathrm{H}$ deprotonation.

\section{Unfavorable Mutations for the Synthesis of L- $\alpha$-Alkyl- $\beta$-Phenylserines}

The conserved residue $\mathrm{H} 85$ in LTAaj has an important multifunctional role to (1) coordinate a catalytic water molecule in the active site (di Salvo et al., 2014), (2) to control the electrophilic properties of the PLP ring (Fesko et al., 2018), and (3) to maintain the diastereoselectivity. Although the H85F mutant was active in the aldol addition of $\mathbf{1 a}$ to $2 \mathbf{a}$, the mutant was inactive in the reaction with non-natural donors. The same is true for other variants, which have an impact on the electrophilic properties of the PLP cofactor (N64I, H85F, E138A, $\mathrm{R} 171 \mathrm{~T}$, and $\mathrm{R} 313 \mathrm{H}$ ) - they were not active in the synthesis of $\alpha$ alkyl- $\beta$-phenylserines 3b-c (Table 1). This indicates that $C_{\alpha}-C_{\beta}$ 
bond formation in the case of $\mathrm{C}_{\alpha}$-substituted donors occurs with significantly lower rates in comparison to the glycine donor, thus $\mathrm{C}_{\alpha}$ carbanion stabilization by the conjugated PLP system is essential for the catalytic activity with non-natural donors. Therefore, a different set of mutations is needed for improving the synthesis of either L- $\beta$-phenylserine or L- $\alpha$-alkyl$\beta$-phenylserines.

\section{DISCUSSION}

L-threonine aldolases are promising catalysts for the environmentally friendly enzymatic synthesis of enantiopure non-natural amino acids. However, the biotechnological application of the wild type aldolases is hampered by the thermodynamic and kinetic limitations leading to low diastereoselectivity and product yield. We performed sitedirected mutagenesis of the active site residues of L-threonine aldolase from Aeromonas jandaei and the mutants were functionally characterized in order to elucidate the impact of each residue on the catalytic activity in the retro-aldol cleavage reaction as well as for the synthesis of L- $\beta$-hydroxy- $\alpha$-amino acids. We have found, that positions which are important for the carbanion stabilization (e.g., N64, H85, E138, R171, R313) significantly reduce the specific activity in the cleavage reaction, whereas a high synthetic capacity to produce L- $\beta$-phenylserine is maintained. Thus, for the efficient retro-aldol cleavage process catalyzed by LTA, $\mathrm{C}_{\alpha}$-carbanion has to be stabilized, whereas this is much less important in the aldol process. The suppression of the retro-aldol activity makes the aldol reaction virtually irreversible. Therefore, these conditions affect the kinetics of the reaction improving the diastereoselectivity and increasing the final conversion to the aldol adducts. Consequently, we could remarkably improve the conversion in the aldol addition of benzaldehyde to glycine from 20 to $60 \%$ by applying mutants with low retro-aldol activity. Moreover, L-anti- $\beta$-phenylserine can be obtained as the major isomer under kinetically controlled conditions with $\mathrm{H} 85 \mathrm{~F}$ and $\mathrm{R} 313 \mathrm{~F}$ mutants.

This observation is essential for designing screening experiments to discover new efficient LTA variants. The currently applied screening procedures are mainly based on the detection of initial velocities in the cleavage of a product of interest, where the variants with low retro-aldol activity will be overlooked. However, such variants might be beneficial to run the aldol reaction under kinetic control to allow product accumulation with higher yield. Thus, screening techniques where the formation of the product is monitored should be applied to observe the mutants with improved performance in the aldol reaction.

In contrast, in the aldol reactions with non-natural donors, the $\mathrm{C}_{\alpha}$-carbanion stabilization is essential. The mutations, which are beneficial for the conversion in the synthesis of $L-\beta$-phenylserine, turned out to be deleterious for the aldol synthesis of L- $\alpha$ alkyl- $\beta$-phenylserine. Further, we have found that a hydrophobic environment of the aldehyde binding pocket is important for an efficient progress of the aldol reaction. The T10A, V31T, Y32M, R231A mutants enlarge the active site pocket to accommodate the side chain of a donor and provide a favorable surrounding to stabilize the donor for $\mathrm{C}_{\alpha}-\mathrm{H}$ abstraction, and thus, increase the donor specificity. We have found that due to the high flexibility of the active site of LTAaj, an amino acid donor has to be specifically fixed in the active site to support $\mathrm{C}_{\alpha}-\mathrm{H}$ abstraction. For each donor molecule, different sets of mutations/positions exist, that favor the donor's binding in an appropriate orientation. Thus, substrate binding should be specifically modulated and rationally designed toward the donor of interest. Here we showed the double mutant R231A/Y32M evolves novel donor specificity of LTAaj to accept D-aminobutanoic acid, D-threonine, and Dnorvaline. Although the described mutants are still not suitable for the synthetic applications, they can be used as a starting point for further enzyme engineering with respect to $\alpha$-quaternary- $\alpha$ amino acids.

In conclusion, the protein engineering and knowledge of the catalytic function of active site residues facilitated the elucidation of novel LTAaj variants with increased productivity for the synthesis of $\mathrm{L}-\beta$-phenylserine and $\mathrm{L}-\alpha$-alkyl- $\beta$-phenylserine. LTAaj accepts a wide range of aldehyde substrates and the conversion in the aldol reaction depends very much on the nature of the aldehyde substrate used. Thus, upon application of an improved variant with a good electrophile substrate such as 3nitro-benzaldehyde conversion up to $100 \%$ can be reached in the aldol reactions catalyzed by LTAaj.

\section{DATA AVAILABILITY}

All datasets generated for this study are included in the manuscript and/or the Supplementary Files.

\section{AUTHOR CONTRIBUTIONS}

The author confirms being the sole contributor of this work and has approved it for publication.

\section{FUNDING}

The Austrian science fund FWF is kindly acknowledged for financial support (Hertha-Firnberg project T735-B21).

\section{ACKNOWLEDGMENTS}

Prof. Rolf Breinbauer and Dr. Gernot Strohmeier are acknowledged for their ideas and support in the preparing this manuscript.

\section{SUPPLEMENTARY MATERIAL}

The Supplementary Material for this article can be found online at: https://www.frontiersin.org/articles/10.3389/fbioe. 2019.00119/full\#supplementary-material 


\section{REFERENCES}

Baltz, R. H., Miao, V., and Wrigley, S. K. (2005). Natural products to drugs: daptomycin and related lipopeptide antibiotics. Nat. Prod. Rep. 22, 717-741. doi: 10.1039/b416648p

Blesl, J., Trobe, M., Anderl, F., Breinbauer, R., Strohmeier, G. A., and Fesko, K. (2018). Application of threonine aldolases for the asymmetric synthesis of $\alpha$-quaternary $\alpha$-amino acids. ChemCatChem $10,3453-3458$. doi: $10.1002 /$ cctc. 201800611

Breuer, M., Ditrich, K., Habicher, T., Hauer, B., Keßeler, M., Stürmer, R., et al. (2004). Industrial Methods for the Production of Optically Active Intermediates. Angew. Chemie 43, 788-824. doi: 10.1002/anie.200300599

Bulut, D., Gröger, H., and Hummel, W. (2015). Development of a growthdependent selection system for identification of L-threonine aldolases. Appl. Microbiol. Biotech. 99, 5875-5883. doi: 10.1007/s00253-014-6333-z

di Salvo, M. L., Remesh, S. G., Vivoli, M., Ghatge, M. S., Paiardini, A., D’Aguanno, S., et al. (2014). On the Catalytic Mechanism and Stereospecificity of Escherichia Coli L-threonine aldolase. FEBS J. 281, 129-145. doi: 10.1111/febs.12581

Dückers, N., Baer, K., Simon, S., Gröger, H., and Hummel, W. (2010). Threonine aldolases-screening, properties and applications in the synthesis of nonproteinogenic b-hydroxy-a-amino acids. Appl. Microbiol. Biotech. 88, 409-424. doi: 10.1007/s00253-010-2751-8

Fesko, K. (2016). Threonine aldolases: perspectives in engineering and screening the enzymes with enhanced substrate and stereo specificities. Appl. Microbiol. Biotech. 100, 2579-2590. doi: 10.1007/s00253-015-7218-5

Fesko, K., and Gruber-Khadjawi, M. (2013). Biocatalytic methods for C-C bond formation. ChemCatChem 5, 1248-1272. doi: 10.1002/cctc.201200709

Fesko, K., Reisinger, C., Steinreiber , J., Weber, H., Schürmann, M., and Griengl, H. (2008). Four types of threonine aldolases: similarities and differences in kinetics/thermodynamics. J. Mol. Cat. B: Enzym. 52-53, 19-26. doi: $10.1016 /$ j.molcatb.2007.10.010

Fesko, K., Strohmeier, G. A., and Breinbauer, R. (2015). Expanding the threonine aldolase toolbox for the asymmetric synthesis of tertiary $\alpha$-amino acids. Appl. Microbiol. Biotech. 99, 9651-9661. doi: 10.1007/s00253-015$6803-y$

Fesko, K., Suplatov, D., and Švedas, V. (2018). Bioinformatic analysis of the fold type I PLP-dependent enzymes reveals determinants of reaction specificity in L-threonine aldolase from Aeromonas jandaei. FEBS Open Bio 8, 1013-1028. doi: 10.1002/2211-5463.12441

Fesko, K., Uhl, M., Steinreiber, J., Gruber, K., and Griengl, H. (2010). Biocatalytic access to a,a-dialkyl-a-amino acids by a mechanism-based approach. Angew. Chemie. 49, 121-24. doi: 10.1002/anie.200904395

Franz, S. E., and Stewart, J. D. (2014). "Threonine aldolases," in Advances in Applied Microbiology, eds S. Sariaslani and G. M. Gadd (London: Academic Press), 57-101. doi: 10.1016/B978-0-12-800260-5.00003-6

Giger, L., Toscano, M. D., Bouzon, M., Marlière, P., and Hilvert, D. (2012). A novel genetic selection system for PLP-dependent threonine aldolases. Tetrahedron 68, 7549-7557. doi: 10.1016/j.tet.2012.05.097
Goldstein, D. S. (2006). L-Dihydroxyphenylserine (L-DOPS): a norepinephrine prodrug. Cardiovasc. Drug Rev. 24, 189-203. doi: 10.1111/j.1527-3466.2006.00189.x

Gutierrez, M. L., Garrabou, X., Agosta, E., Servi, S., Parella, T., Joglar, J., et al. (2008). Serine hydroxymethyl transferase from Streptococcus thermophilus and L-threonine aldolase from Escherichia coli as stereocomplementary biocatalysts for the synthesis of $\beta$-hydroxy- $\alpha, \omega$-diamino acid derivatives. Chem. Eur. J. 14, 4647-4656. doi: 10.1002/chem.200800031

Hernandez, K., Zelen,I., Petrillo, G., Usón, I., Wandtke, C. M., Bujons, J., et al. (2015). Engineered L-serine hydroxymethyltransferase from Streptococcus Thermophilus for the synthesis of $\alpha, \alpha$-dialkyl- $\alpha$-amino acids. Angew. Chemie. 54, 3013-17. doi: 10.1002/anie.201411484

Kielkopf, C. L., and Burley, S. K. (2002). X-ray structures of threonine aldolase complexes: structural basis of substrate recognition. Biochemistry 41 , 11711-11720. doi: 10.1021/bi020393+

Liu, G., Zhang, M., Chen, X., Zhang, W., Ding, W., and Zhang, Q. (2015). Evolution of threonine aldolases, a diverse family involved in the second pathway of glycine biosynthesis. J. Mol. Evol. 80, 102-107. doi: 10.1007/s00239-015-9667-y

Panke, S., and Wubbolts, M. (2005). Advances in biocatalytic synthesis of pharmaceutical intermediates. Curr. Opin. Chem. Biol. 9, 188-194. doi: 10.1016/j.cbpa.2005.02.007

Qin, H.-M., Imai, F. L., Miyakawa, T., Kataoka, M., Kitamura, N., Urano, N., et al. (2014). L-allo-threonine aldolase with an H128Y/S292R mutation from Aeromonas Jandaei DK-39 reveals the structural basis of changes in substrate stereoselectivity. Acta Crystal. Sec. D Biol. Crystal. 70, 1695-1703. doi: 10.1107/S1399004714007664

Reisinger, C., Kern, A., Fesko, K., and Schwab, H. (2007). An efficient plasmid vector for expression cloning of large numbers of PCR fragments in Escherichia Coli. Appl. Microbiol. Biotech. 77, 241-244. doi: 10.1007/s00253-007-1151-1

Steinreiber, J., Fesko, K., Mayer, C., Reisinger, C., Schürmann, M., and Griengl, H. (2007a). Synthesis of $\gamma$-halogenated and long-chain $\beta$-hydroxy- $\alpha$-amino acids and 2-amino-1,3-diols using threonine aldolases. Tetrahedron 63, 8088-8093. doi: $10.1016 /$ j.tet.2007.06.013

Steinreiber, J., Fesko, K., Reisinger, C., Schürmann, M., van Assema, F., Wolberg, M., et al. (2007b). Threonine aldolases - an emerging tool for organic synthesis. Tetrahedron 63, 918-926. doi: 10.1016/j.tet.2006.11.035

Conflict of Interest Statement: The author declares that the research was conducted in the absence of any commercial or financial relationships that could be construed as a potential conflict of interest.

Copyright (๑) 2019 Fesko. This is an open-access article distributed under the terms of the Creative Commons Attribution License (CC BY). The use, distribution or reproduction in other forums is permitted, provided the original author(s) and the copyright owner(s) are credited and that the original publication in this journal is cited, in accordance with accepted academic practice. No use, distribution or reproduction is permitted which does not comply with these terms. 